\title{
Optimum Utilization of Energy Consumption in Arm Robot
}

\author{
Hairol Nizam Mohd Shah ${ }^{1}$, Zalina Kamis ${ }^{1}$, Ahmad Zaki Shukor ${ }^{1}$, Mohd Rizuan Baharon ${ }^{2}$, Marizan Sulaiman ${ }^{1}$ \& \\ Wan Nur Farhana Wan Azahari ${ }^{1}$ \\ ${ }^{1}$ Center for Robotics and Industrial Automation, Faculty of Electrical Engineering, Universiti Teknikal Malaysia \\ Melaka, Malaysia \\ ${ }^{2}$ Department of Computer System and Communication, Faculty of Communication and Information Technology, \\ Universiti Teknikal Malaysia Melaka, Malaysia \\ Correspondence: Hairol Nizam Mohd Shah, Center for Robotics and Industrial Automation, Faculty of Electrical \\ Engineering, Universiti Teknikal Malaysia Melaka, Malaysia. E-mail: hnizam@utem.edu.my
}

Received: February 8, 2019

Accepted: March 9, 2019

Online Published: April 30, 2019

doi:10.5539/mas.v13n5p57

URL: https://doi.org/10.5539/mas.v13n5p57

\begin{abstract}
This paper introduced on how to minimize the energy and performance of arm robot. The objective is to design the optima; performance of the arm robot movement in performing certain tasks. There are three process involved in minimize the energy which are hardware assembly selection, Denavit Haternberg (D-H) parameters and optimization process of robot movements. A 3 degree of freedom ROB0036 robot arm is use as hardware selection. Then determine the Denavit Haternberg (D-H) parameters for robot through theoretical, simulation and practical forward and inverse kinematics. The optimization process involved how to control parameters know as position angle and the speed of motor of three main axes of arm robot. The performance is measured respect to the two movement, which are reference and optimized. The energy efficiency analysis is performs to reduce this energy consumed. The simulation resulted show that the minimum motor's movement of joint, the less time taken to achieve of to complete the pick and place task. Directly, it results on less energy used and increase the robot arm performance.
\end{abstract}

Keywords: energy optimization, robot arm, D-H parameter, kinematics, trajectory planning

\section{Introduction}

The Robot arm or manipulator is a mechanical device which driven by different actuators either motor, pneumatic or hydraulic. The motion model decides the geometric forms include the Cartesian, Cylindrical, Spherical or Articulated coordinate (Tong Zou, 2011). Robotic manipulators commonly being used for handling repetitive tasks where their operation handled by simple position control strategies. It is vital to automate the manipulation operation in order to expand the applications of pick and place robotic arm. In robotic arm, it is important to find the optimal dynamic performances of the robot through the primary process by knowing the structure of its kinematic. Bowling at al. (1997) reported by implementing the forward and inverse kinematic analysis of the robot, an exact position and orientation for each of its movement could be identify. To make it, the best position and orientation for optimal performance needed to achieve the target or object can be find.

In order to reduce the energy consumption, an analytical solution was perform to follow the specific trajectory of robot arm. Therefore, the joints are operate with respect to time. The joint movements can be simple or complex. Here, the forward and inverse kinematic are analyzed specifically and systematically. The objective of the analysis is to determine the effect of changes of the entire set of joint variables to the electrical energy consumed at each joints.

\section{Related Work}

\subsection{Trajectory Planning}

The idea of optimization and minimization technique for the electrical energy consumed specifically in robotic arm field is recently been developed. It requires a big deal of kinematic calculation in performing the application of arm robot and flexible to adapt with any changes happened in robotic arm design. All the prior research based on the calculation of inverse kinematic that consider a pseudo inverse of Jacobian matrix and few criterion. For example, Nakamura and Hanafusa (1987) studied the generalized inverse of Jacobian matrix (Nakamura et al., 
1987). Oda had conduct a study on simplified method for calculation of the inverse kinematic including all space calculation and workspace observer (Oda et al., 1995). Besides, the trajectory planning in the joint space is modeled as a B-Spline curve and the performance index is directly integrated through the desired trajectory of the endeffector which is the new scheme based on the variation approach.

\subsection{Kinematic}

Appropriate Kinematic is the geometry of motions with respect to the reference coordinate system without regards to the forces that cause it. The kinematic involves displacement, position (angle), velocity and acceleration. Figure 1 show the model of robot arm.

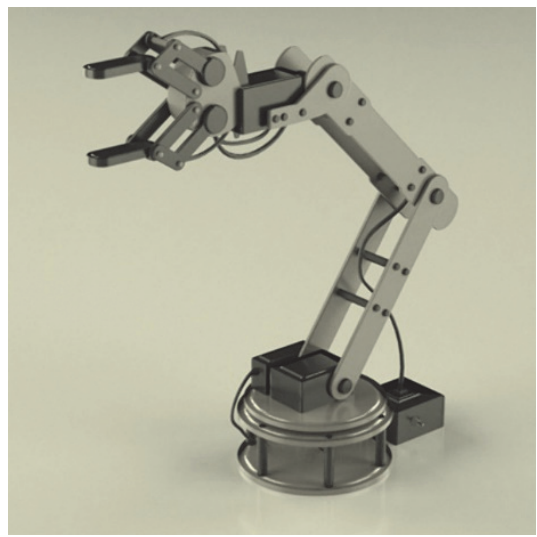

Figure 1. Model of robot arm

\subsubsection{Forward Kinematic}

Describe Forward kinematics problem is dealing with finding the position and orientation of a robot end effector as a function of its joint angles. The Denavit-Haternberg (D-H) is the matrices associated with these operations (MNFM Kazim et al., 2015; Marizan et al., 2013). The kinematics result in a sequence of rigid transformation of the alternating joint and link form the base to the end of its link, which is equal to the specified position of the end link.

\subsubsection{Inverse Kinematic}

Inverse kinematic deals with the problem of findings the appropriated joint angles to get the desired position and orientation of the end effector. Generally, the inverse kinematics solutions are non-linear. In order to find those equations can be complicated and sometimes no solution being found. One of the technique that has be used to find the exact angles of each joint to reach the target by using the Geometrical approach.

\subsection{Geometric Solution}

One of the simple ways to solve the inverse kinematics problem is by using geometric solution. In geometric approach, to find a manipulator's solution, the spatial geometry of the arm need to be decomposed into several plane geometry problems. A free body diagram of this arm created by representing each of the joints as a translational symbol and showing the links connecting each joint as a line. To model this system, it is necessary to know how any degree of freedom are associated with the arm, it is sufficient to count the number of controllable joints in order to determine the DOF (Kurt et al., 2010).

The figure shows triangle formed by $l_{1}, l_{2}$ and the line joining the origin of frame $\{0\}$ with the frame $\{3\}$. The dashed lines represent the other possible configuration of the triangle that lead to the same position of the frame $\{3\}$. Through this method, the law of cosine was applied to solve the $\theta_{2}$.

Then,

$$
\mathrm{x}^{2}+\mathrm{y}^{2}=\mathrm{l}_{1}^{2}+\mathrm{l}_{2}^{2}-2 \mathrm{l}_{1} \mathrm{l}_{2} \cos \left(180+\theta_{2}\right)
$$

So,

$$
\cos \left(180+\theta_{2}\right)=\mathrm{c} 2=\frac{\mathrm{x}^{2}+\mathrm{y}^{2}-\mathrm{l}_{1}{ }^{2}-\mathrm{l}_{2}^{2}}{2 \mathrm{l}_{1} \mathrm{l}_{2}}
$$

In order for this triangle to exist, the distance to the goal point $\sqrt{x^{2}+y^{2}}$ must be less or equal to the sum of the lengths, $l_{1}+l_{2}$. The condition was record at this point to verify existence of solutions. This is not satisfied 
if the target point is out of reach of the solutions. By assume the existence of solutions, the value of $\theta_{2}$ in Eq. 1 must lies between 0 and -180 degrees. It is because only for these values does the triangle exist.

\subsection{Robot Programming Language}

The Arduino programming is very simple (HNM Shah et al., 2014) and it depend on the complexity of the research. Its platform can be program using its own language based on the high-level programming languages and support all the standard $\mathrm{C}$ and $\mathrm{C}++$ functions. Hernandez et al. (2010) designed a wireless control system robot using Arduino which allow a simple implementation and low power consumption of system. It helps the robot to control with freedom of movement. Figure 2 shows the main components of Arduino that has be used.

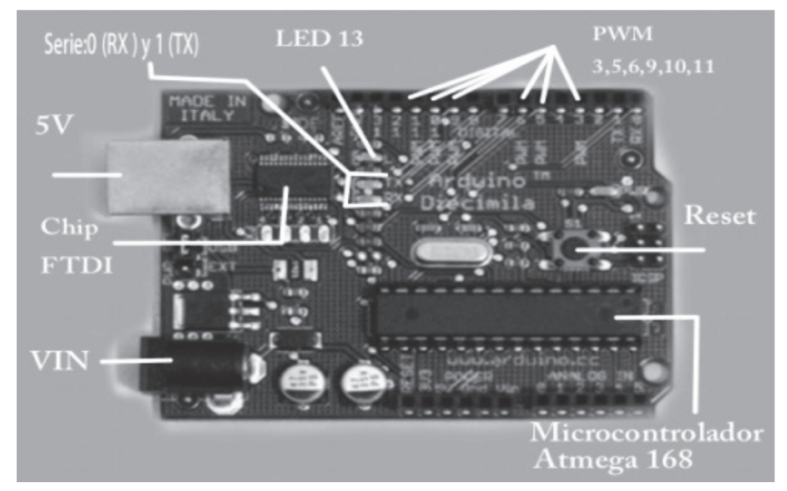

Figure 2. Main components of Arduino

\subsection{Power Measurement}

In order to minimize the energy consumption of the grasping process, Howon, (2012) reported the total energy consumed by the manipulators need to estimated for the specific posture. The motor driven is control by Pulse Width Modulation (PWM) method with the specific voltage. Here, the average current for each joint will be proportional to the power consumed is show in Eq. 4 .

$$
P=I V
$$

where,

$I$ is the summation of the currents at each joints.

$V$ is the constant value for the voltage.

\section{Method}

The research methodology flowchart is shows in Figure 3. It is consists of the planning of project flow, research methodology based on the previous research, development of algorithm using Arduino, the integration of program with hardware and optimizing the energy consumption of the robot manipulator. To develop and demonstrate the approach in the real experiments, the arm robot of ROB0036 has be used. 


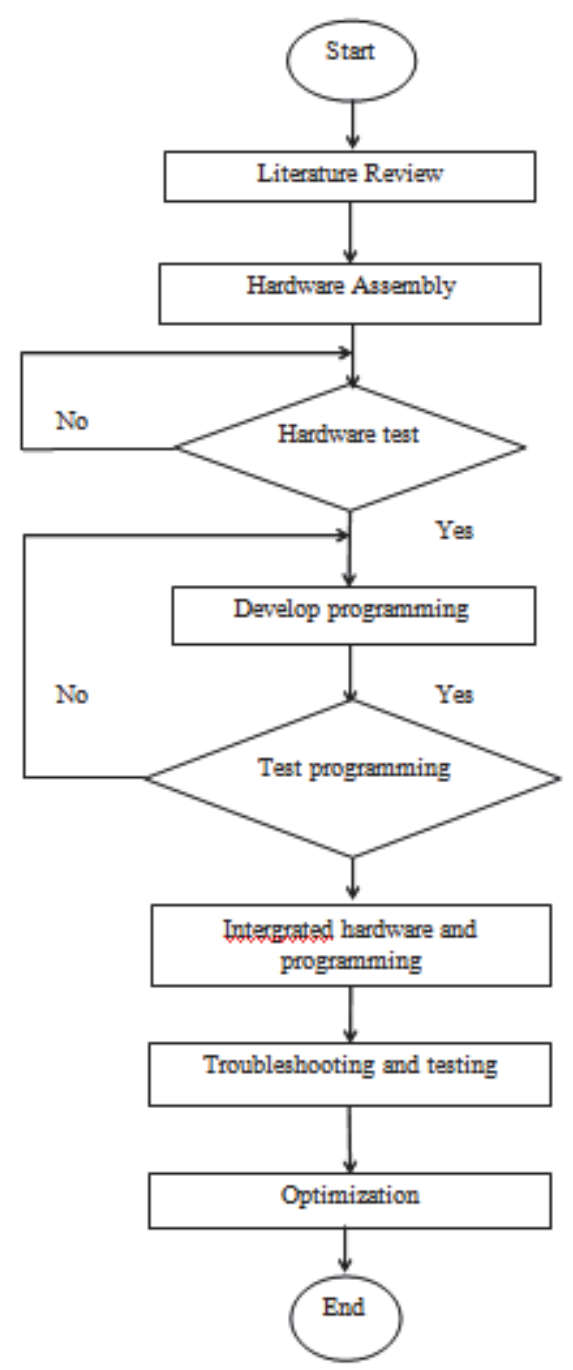

Figure 3. Research methodology flow chart

\subsection{Hardware}

\subsubsection{Hardware Assembly}

The hardware component and arm robot assembly is show in Figure 4 to 6 . In servo motor there are three wires coming out of them. Figure 7 shows the color of cable for servo motor that being used in the robot joint.

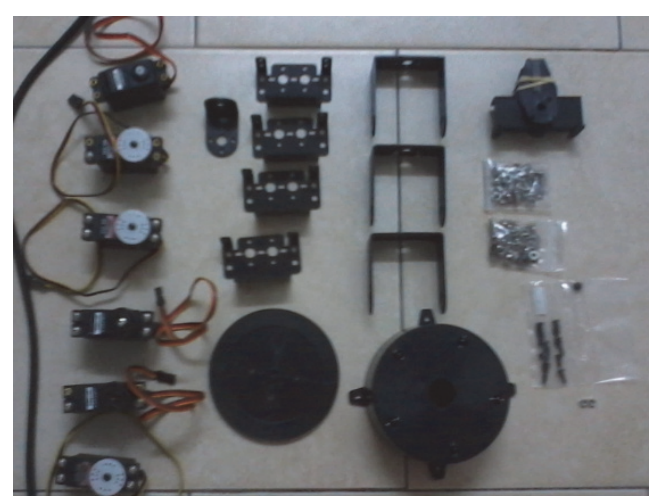

Figure 4. Components of arm robot 


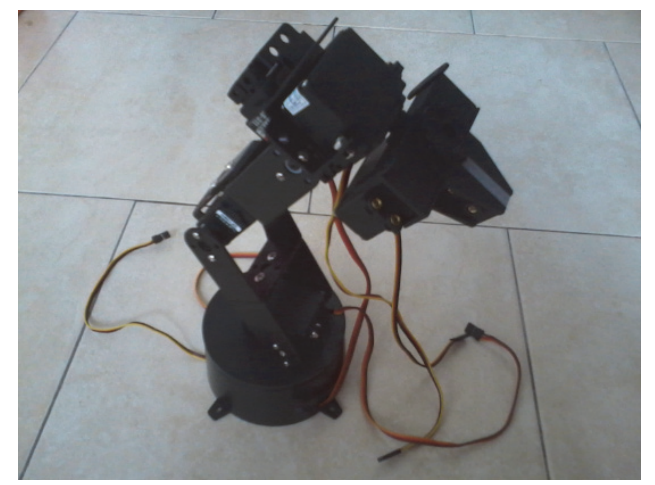

Figure 5: Arm robot

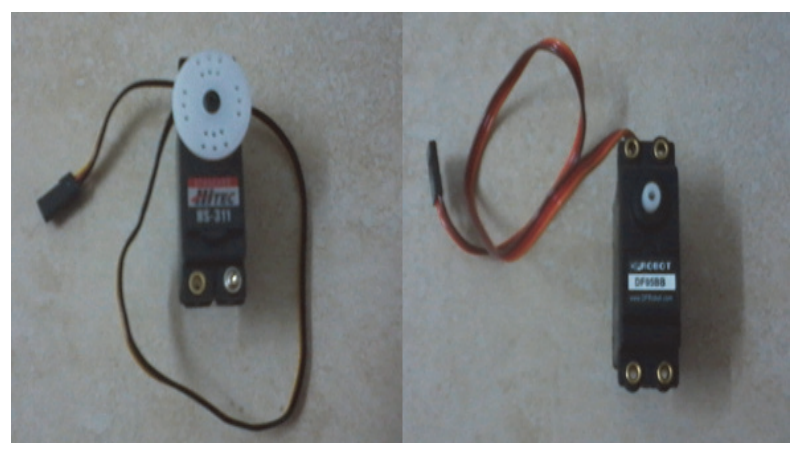

Figure 6: Servo motor

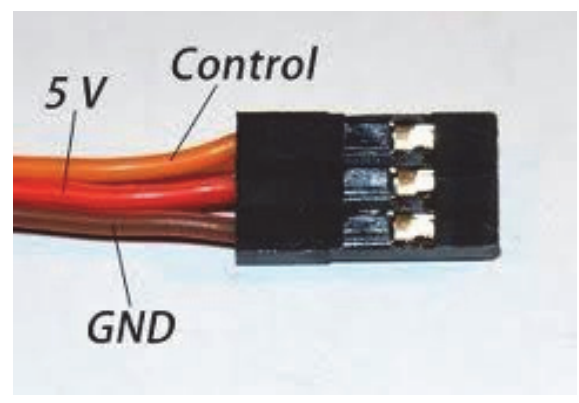

Figure 7. Cable of servo motor

The output shaft of the servo motor is capable to rotate in the range of 180 degrees. The amount of power supplied to the motor by the battery is proportional to the distance it needs to travel. This is knowns as a proportional control method.

The control wire or signal wire is used to communicate the angle of servo motor. The angle is being determined by the duration of a pulse from the controller to the signal wire. This method called a Pulse Width Modulation. The servo motor is defined to see a pulse after every 20 milliseconds and the length of the pulse declared as how long the motor will turn to the position (pos).

\subsubsection{Designing the Circuit Connection}

The designing of connection circuit for arm robot involved several components such as DC servo motors, wire, potentiometer and controller using Fritzing. Figure 8 shows the circuit connection using Fritzing. 


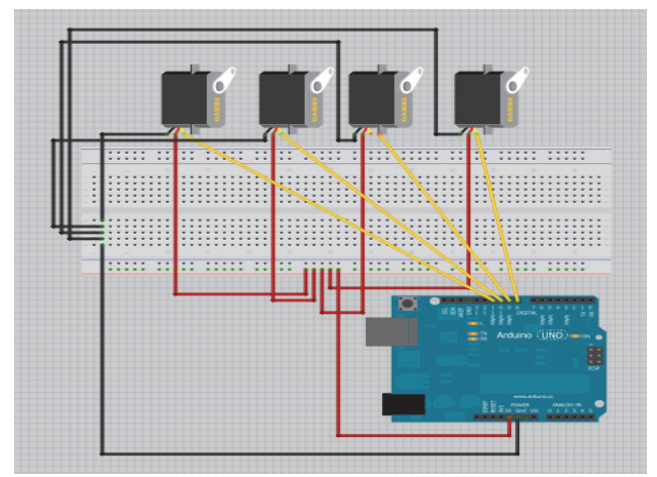

Figure 8. Designing circuit connection using Fritzing

Arduino is a single board microcontroller that typically used to make a process using electronics devices in multidisciplinary projects. It is an open source computing platform based on the very simple input and output board. In the process to develop the algorithm for robot motion, the new Arduino Uno R3 is used. The Arduino Uno R3 microcontroller is shows in Figure 9. This kind of microcontroller uses an Atmega 16U2 instead of 8U2 that be found in the most of Uno available in the previous generations (HNM Shah et al., 2018a; 2018b). It allows for the faster transfer rates and more memory space available. In addition, Uno has the ability to show up by using keyboard, joystick and etc. The circuit connection assembly is shows in Figure 10.

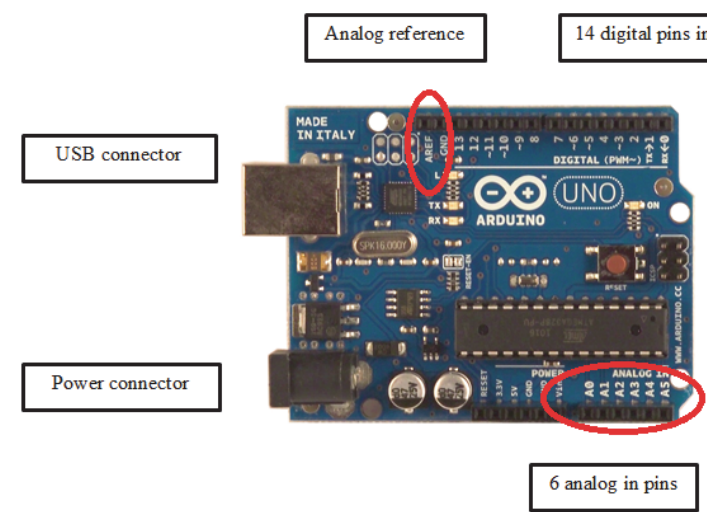

Figure 9. Arduino Uno R3 microcontroller

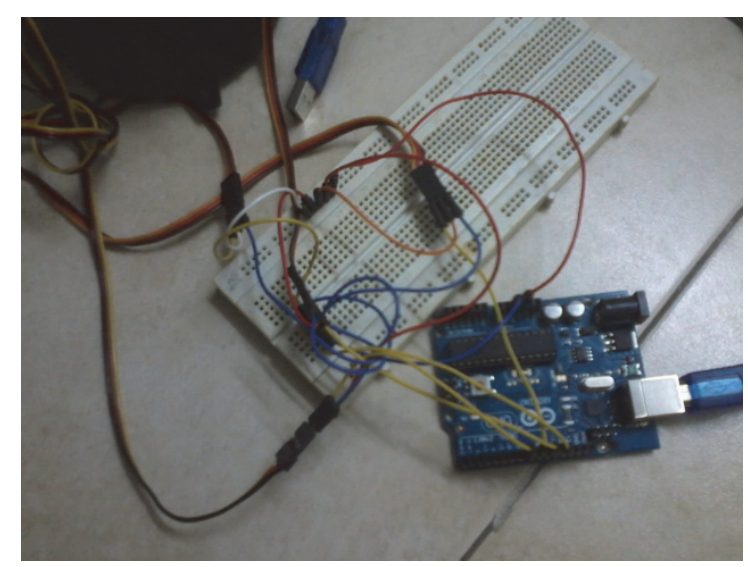

Figure 10. Circuit connection assembly 


\subsection{Software Configuration}

\subsubsection{Arduino}

An algorithm was develop to enable the robot manipulator move to perform the desired task. The Arduino 1.0.3 software consist of a standard programming language compiler and a boot loader that will executed on the microcontroller after the algorithm uploaded into it as shows in Figure 11.

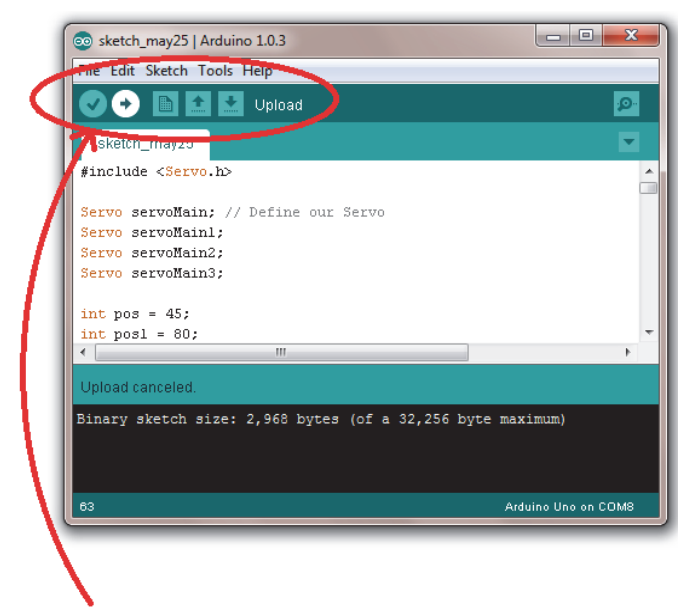

Figure 11. Algorithm upload

\section{Results}

To verify the variable potentiometer, three experiments that have been conducted related with digital As a result, the performance is measured respect to the two movement, which are reference and optimized. The reading of the current flow and the power consumed for each complete cycle before and after optimization will be record. The current reading was record every 3 minutes, 9 minutes and 12 minutes for 15 time complete cycles. Table 1(a) (e) represent the parameters reading before arm robot optimization process done while Table 1(f) - (j) represent the parameters reading after arm robot optimization process. The experiment results is take for 15 time cycles.

Table 1(a). before optimization at 3 minutes

\begin{tabular}{ccccc}
\hline Cycle & $\begin{array}{c}\text { Voltage } \\
\text { (Volt) }\end{array}$ & $\begin{array}{c}\text { Current } \\
\text { (Ampere) }\end{array}$ & $\begin{array}{c}\text { Power } \\
\text { (Watt) }\end{array}$ & $\begin{array}{c}\text { Time } \\
\text { (sec) }\end{array}$ \\
\hline 1 & 5.06 & 0.124 & 0.627 & 14.6 \\
2 & 5.06 & 0.125 & 0.633 & 14.7 \\
3 & 5.06 & 0.124 & 0.627 & 14.6 \\
4 & 5.06 & 0.124 & 0.627 & 14.6 \\
5 & 5.06 & 0.123 & 0.622 & 14.5 \\
6 & 5.06 & 0.123 & 0.622 & 14.5 \\
7 & 5.06 & 0.123 & 0.622 & 14.5 \\
8 & 5.06 & 0.123 & 0.622 & 14.5 \\
9 & 5.06 & 0.124 & 0.627 & 14.6 \\
10 & 5.06 & 0.124 & 0.627 & 14.6 \\
11 & 5.06 & 0.123 & 0.622 & 14.5 \\
12 & 5.06 & 0.122 & 0.617 & 14.4 \\
13 & 5.06 & 0.122 & 0.617 & 14.4 \\
14 & 5.06 & 0.123 & 0.622 & 14.5 \\
15 & 5.06 & 0.122 & 0.617 & 14.4 \\
Average & $\mathbf{5 . 0 6}$ & $\mathbf{0 . 1 2 2}$ & $\mathbf{0 . 6 2 3}$ & $\mathbf{1 4 . 5 3}$ \\
\hline
\end{tabular}


Table 1(b). Before optimization at 6 minutes

\begin{tabular}{ccccc}
\hline Cycle & $\begin{array}{c}\text { Voltage } \\
\text { (Volt) }\end{array}$ & $\begin{array}{c}\text { Current } \\
\text { (Ampere) }\end{array}$ & $\begin{array}{c}\text { Power } \\
\text { (Watt) }\end{array}$ & $\begin{array}{c}\text { Time } \\
\text { (sec) }\end{array}$ \\
\hline 1 & 5.06 & 0.125 & 0.633 & 14.7 \\
2 & 5.06 & 0.125 & 0.633 & 14.7 \\
3 & 5.06 & 0.124 & 0.627 & 14.6 \\
4 & 5.06 & 0.123 & 0.622 & 14.5 \\
5 & 5.06 & 0.124 & 0.627 & 14.6 \\
6 & 5.06 & 0.124 & 0.627 & 14.6 \\
7 & 5.06 & 0.123 & 0.622 & 14.5 \\
8 & 5.06 & 0.123 & 0.622 & 14.5 \\
9 & 5.06 & 0.124 & 0.627 & 14.6 \\
10 & 5.06 & 0.122 & 0.617 & 14.4 \\
11 & 5.06 & 0.123 & 0.622 & 14.5 \\
12 & 5.06 & 0.123 & 0.622 & 14.5 \\
13 & 5.06 & 0.122 & 0.617 & 14.4 \\
14 & 5.06 & 0.123 & 0.622 & 14.5 \\
15 & 5.06 & 0.122 & 0.617 & 14.4 \\
Average & $\mathbf{5 . 0 6}$ & $\mathbf{0 . 1 2 3}$ & $\mathbf{0 . 6 2 4}$ & $\mathbf{1 4 . 5 3}$ \\
\hline
\end{tabular}

Table 1(c). Before optimization at 9 minutes

\begin{tabular}{ccccc}
\hline Cycle & $\begin{array}{c}\text { Voltage } \\
\text { (Volt) }\end{array}$ & $\begin{array}{c}\text { Current } \\
\text { (Ampere) }\end{array}$ & $\begin{array}{c}\text { Power } \\
\text { (Watt) }\end{array}$ & $\begin{array}{c}\text { Time } \\
\text { (sec) }\end{array}$ \\
\hline 1 & 5.06 & 0.125 & 0.633 & 14.7 \\
2 & 5.06 & 0.125 & 0.633 & 14.7 \\
3 & 5.06 & 0.124 & 0.627 & 14.6 \\
4 & 5.06 & 0.124 & 0.627 & 14.6 \\
5 & 5.06 & 0.123 & 0.622 & 14.5 \\
6 & 5.06 & 0.124 & 0.627 & 14.6 \\
7 & 5.06 & 0.124 & 0.627 & 14.6 \\
8 & 5.06 & 0.123 & 0.622 & 14.5 \\
9 & 5.06 & 0.123 & 0.622 & 14.5 \\
10 & 5.06 & 0.122 & 0.617 & 14.4 \\
11 & 5.06 & 0.124 & 0.627 & 14.6 \\
12 & 5.06 & 0.123 & 0.622 & 14.5 \\
13 & 5.06 & 0.123 & 0.622 & 14.5 \\
14 & 5.06 & 0.123 & 0.622 & 14.5 \\
15 & 5.06 & 0.122 & 0.617 & 14.4 \\
Average & $\mathbf{5 . 0 6}$ & $\mathbf{0 . 1 2 3}$ & $\mathbf{0 . 6 2 5}$ & $\mathbf{1 4 . 5 5}$ \\
\hline
\end{tabular}


Table 1 (d). Before optimization at 12 minutes

\begin{tabular}{ccccc}
\hline Cycle & $\begin{array}{c}\text { Voltage } \\
\text { (Volt) }\end{array}$ & $\begin{array}{c}\text { Current } \\
\text { (Ampere) }\end{array}$ & $\begin{array}{c}\text { Power } \\
\text { (Watt) }\end{array}$ & $\begin{array}{c}\text { Time } \\
\text { (sec) }\end{array}$ \\
\hline 1 & 5.06 & 0.125 & 0.633 & 14.7 \\
2 & 5.06 & 0.125 & 0.633 & 14.7 \\
3 & 5.06 & 0.125 & 0.633 & 14.7 \\
4 & 5.06 & 0.124 & 0.627 & 14.6 \\
5 & 5.06 & 0.125 & 0.633 & 14.7 \\
6 & 5.06 & 0.124 & 0.627 & 14.6 \\
7 & 5.06 & 0.124 & 0.627 & 14.6 \\
8 & 5.06 & 0.124 & 0.627 & 14.6 \\
9 & 5.06 & 0.123 & 0.622 & 14.5 \\
10 & 5.06 & 0.123 & 0.622 & 14.5 \\
11 & 5.06 & 0.124 & 0.627 & 14.6 \\
12 & 5.06 & 0.123 & 0.622 & 14.5 \\
13 & 5.06 & 0.123 & 0.622 & 14.5 \\
14 & 5.06 & 0.122 & 0.617 & 14.4 \\
15 & 5.06 & 0.123 & 0.622 & 14.5 \\
Average & $\mathbf{5 . 0 6}$ & $\mathbf{0 . 1 2 4}$ & $\mathbf{0 . 6 2 6}$ & $\mathbf{1 4 . 5 8}$ \\
\hline
\end{tabular}

Table 1 (e). Before optimization at 15 minutes

\begin{tabular}{ccccc}
\hline Cycle & $\begin{array}{c}\text { Voltage } \\
\text { (Volt) }\end{array}$ & $\begin{array}{c}\text { Current } \\
\text { (Ampere) }\end{array}$ & $\begin{array}{c}\text { Power } \\
\text { (Watt) }\end{array}$ & $\begin{array}{c}\text { Time } \\
\text { (sec) }\end{array}$ \\
\hline 1 & 5.06 & 0.125 & 0.633 & 14.7 \\
2 & 5.06 & 0.125 & 0.633 & 14.7 \\
3 & 5.06 & 0.125 & 0.633 & 14.7 \\
4 & 5.06 & 0.124 & 0.627 & 14.6 \\
5 & 5.06 & 0.124 & 0.627 & 14.6 \\
6 & 5.06 & 0.124 & 0.627 & 14.6 \\
7 & 5.06 & 0.123 & 0.622 & 14.5 \\
8 & 5.06 & 0.123 & 0.622 & 14.5 \\
9 & 5.06 & 0.124 & 0.627 & 14.6 \\
10 & 5.06 & 0.124 & 0.627 & 14.6 \\
11 & 5.06 & 0.123 & 0.622 & 14.5 \\
12 & 5.06 & 0.124 & 0.627 & 14.6 \\
13 & 5.06 & 0.123 & 0.622 & 14.5 \\
14 & 5.06 & 0.124 & 0.627 & 14.6 \\
15 & 5.06 & 0.123 & 0.622 & 14.5 \\
Average & $\mathbf{5 . 0 6}$ & $\mathbf{0 . 1 2 4}$ & $\mathbf{0 . 6 2 6}$ & $\mathbf{1 4 . 5 9}$ \\
\hline
\end{tabular}


Table 1 (f). After Optimization at 3 minutes

\begin{tabular}{lllll}
\hline Cycle & $\begin{array}{l}\text { Voltage } \\
\text { (Volt) }\end{array}$ & $\begin{array}{l}\text { Current } \\
\text { (Ampere) }\end{array}$ & $\begin{array}{l}\text { Power } \\
\text { (Watt) }\end{array}$ & $\begin{array}{l}\text { Time } \\
\text { (sec) }\end{array}$ \\
\hline 1 & 5.06 & 0.122 & 0.617 & 12.1 \\
2 & 5.06 & 0.122 & 0.617 & 12.1 \\
3 & 5.06 & 0.121 & 0.612 & 11.9 \\
4 & 5.06 & 0.121 & 0.612 & 11.9 \\
5 & 5.06 & 0.122 & 0.617 & 12.1 \\
6 & 5.06 & 0.121 & 0.612 & 11.9 \\
7 & 5.06 & 0.120 & 0.607 & 11.8 \\
8 & 5.06 & 0.120 & 0.607 & 11.8 \\
9 & 5.06 & 0.121 & 0.612 & 11.9 \\
10 & 5.06 & 0.120 & 0.607 & 11.8 \\
11 & 5.06 & 0.121 & 0.612 & 11.9 \\
12 & 5.06 & 0.120 & 0.607 & 11.8 \\
13 & 5.06 & 0.121 & 0.612 & 11.9 \\
14 & 5.06 & 0.120 & 0.607 & 11.8 \\
15 & 5.06 & 0.121 & 0.612 & 11.9 \\
Average & $\mathbf{5 . 0 6}$ & $\mathbf{0 . 1 2 0}$ & $\mathbf{0 . 6 1 1}$ & $\mathbf{1 1 . 9}$ \\
\hline
\end{tabular}

Table $1(\mathrm{~g})$. After Optimization at 6 minutes

\begin{tabular}{ccccc}
\hline Cycle & $\begin{array}{c}\text { Voltage } \\
\text { (Volt) }\end{array}$ & $\begin{array}{c}\text { Current } \\
\text { (Ampere) }\end{array}$ & $\begin{array}{c}\text { Power } \\
\text { (Watt) }\end{array}$ & $\begin{array}{c}\text { Time } \\
\text { (sec) }\end{array}$ \\
\hline 1 & 5.06 & 0.122 & 0.617 & 12.1 \\
2 & 5.06 & 0.122 & 0.617 & 12.1 \\
3 & 5.06 & 0.121 & 0.612 & 11.9 \\
4 & 5.06 & 0.122 & 0.617 & 12.1 \\
5 & 5.06 & 0.122 & 0.617 & 12.1 \\
6 & 5.06 & 0.121 & 0.612 & 11.9 \\
7 & 5.06 & 0.121 & 0.612 & 11.9 \\
8 & 5.06 & 0.120 & 0.607 & 11.8 \\
9 & 5.06 & 0.121 & 0.612 & 11.9 \\
10 & 5.06 & 0.121 & 0.612 & 11.8 \\
11 & 5.06 & 0.120 & 0.607 & 11.8 \\
12 & 5.06 & 0.121 & 0.612 & 11.9 \\
13 & 5.06 & 0.122 & 0.617 & 12.1 \\
14 & 5.06 & 0.121 & 0.612 & 11.9 \\
15 & 5.06 & 0.121 & 0.612 & 11.9 \\
Average & $\mathbf{5 . 0 6}$ & $\mathbf{0 . 1 2 1}$ & $\mathbf{0 . 6 1 3}$ & $\mathbf{1 1 . 9 5}$ \\
\hline
\end{tabular}


Table 1 (h). After Optimization at 9 minutes

\begin{tabular}{ccccc}
\hline Cycle & $\begin{array}{c}\text { Voltage } \\
\text { (Volt) }\end{array}$ & $\begin{array}{c}\text { Current } \\
\text { (Ampere) }\end{array}$ & $\begin{array}{c}\text { Power } \\
\text { (Watt) }\end{array}$ & $\begin{array}{c}\text { Time } \\
\text { (sec) }\end{array}$ \\
\hline 1 & 5.06 & 0.123 & 0.622 & 12.4 \\
2 & 5.06 & 0.122 & 0.617 & 12.1 \\
3 & 5.06 & 0.121 & 0.612 & 11.9 \\
4 & 5.06 & 0.120 & 0.607 & 11.8 \\
5 & 5.06 & 0.121 & 0.612 & 11.9 \\
6 & 5.06 & 0.122 & 0.617 & 12.1 \\
7 & 5.06 & 0.121 & 0.612 & 11.9 \\
8 & 5.06 & 0.121 & 0.612 & 11.9 \\
9 & 5.06 & 0.120 & 0.607 & 11.8 \\
10 & 5.06 & 0.122 & 0.617 & 12.1 \\
11 & 5.06 & 0.123 & 0.622 & 12.4 \\
12 & 5.06 & 0.121 & 0.612 & 11.9 \\
13 & 5.06 & 0.120 & 0.607 & 11.8 \\
14 & 5.06 & 0.121 & 0.612 & 11.9 \\
15 & 5.06 & 0.122 & 0.617 & 12.1 \\
Average & $\mathbf{5 . 0 6}$ & $\mathbf{0 . 1 2 1}$ & $\mathbf{0 . 6 1 4}$ & $\mathbf{1 2 . 0}$ \\
\hline
\end{tabular}

Table 1 (i). After optimization at 12 minutes

\begin{tabular}{ccccc}
\hline Cycle & $\begin{array}{c}\text { Voltage } \\
\text { (Volt) }\end{array}$ & $\begin{array}{c}\text { Current } \\
\text { (Ampere) }\end{array}$ & $\begin{array}{c}\text { Power } \\
\text { (Watt) }\end{array}$ & $\begin{array}{c}\text { Time } \\
\text { (sec) }\end{array}$ \\
\hline 1 & 5.06 & 0.123 & 0.622 & 12.3 \\
2 & 5.06 & 0.123 & 0.622 & 12.3 \\
3 & 5.06 & 0.122 & 0.617 & 12.1 \\
4 & 5.06 & 0.122 & 0.617 & 12.1 \\
5 & 5.06 & 0.121 & 0.612 & 12.1 \\
6 & 5.06 & 0.120 & 0.607 & 11.8 \\
7 & 5.06 & 0.121 & 0.612 & 11.9 \\
8 & 5.06 & 0.121 & 0.612 & 11.9 \\
9 & 5.06 & 0.120 & 0.607 & 11.8 \\
10 & 5.06 & 0.121 & 0.612 & 11.9 \\
11 & 5.06 & 0.122 & 0.617 & 12.1 \\
12 & 5.06 & 0.123 & 0.622 & 12.4 \\
13 & 5.06 & 0.121 & 0.612 & 11.9 \\
14 & 5.06 & 0.120 & 0.607 & 11.8 \\
15 & 5.06 & 0.121 & 0.612 & 11.9 \\
Average & $\mathbf{5 . 0 6}$ & $\mathbf{0 . 1 2 1}$ & $\mathbf{0 . 6 1 4}$ & $\mathbf{1 2 . 0 2}$ \\
\hline
\end{tabular}


Table 1 (j). After Optimization at 15 minutes

\begin{tabular}{lllll}
\hline Cycle & $\begin{array}{l}\text { Voltage } \\
\text { (Volt) }\end{array}$ & $\begin{array}{l}\text { Current } \\
\text { (Ampere) }\end{array}$ & $\begin{array}{l}\text { Power } \\
\text { (Watt) }\end{array}$ & $\begin{array}{l}\text { Time } \\
\text { (sec) }\end{array}$ \\
\hline 1 & 5.06 & 0.123 & 0.622 & 12.4 \\
2 & 5.06 & 0.123 & 0.622 & 12.3 \\
3 & 5.06 & 0.123 & 0.622 & 12.3 \\
4 & 5.06 & 0.122 & 0.617 & 12.1 \\
5 & 5.06 & 0.122 & 0.617 & 12.1 \\
6 & 5.06 & 0.121 & 0.612 & 11.9 \\
7 & 5.06 & 0.122 & 0.617 & 12.1 \\
8 & 5.06 & 0.121 & 0.612 & 11.9 \\
9 & 5.06 & 0.122 & 0.617 & 12.2 \\
10 & 5.06 & 0.121 & 0.612 & 11.9 \\
11 & 5.06 & 0.121 & 0.612 & 11.9 \\
12 & 5.06 & 0.120 & 0.607 & 11.8 \\
13 & 5.06 & 0.120 & 0.607 & 11.8 \\
14 & 5.06 & 0.121 & 0.612 & 11.9 \\
15 & 5.06 & 0.122 & 0.617 & 12.1 \\
Average & $\mathbf{5 . 0 6}$ & $\mathbf{0 . 1 2 2}$ & $\mathbf{0 . 6 1 5}$ & $\mathbf{1 2 . 0 5}$ \\
\hline
\end{tabular}

The Figure 12 and 13 shows clearly the different of power consumed between before and after the arm robot optimization. Based on the Figure, it shows that the power used is proportional to the time operation.

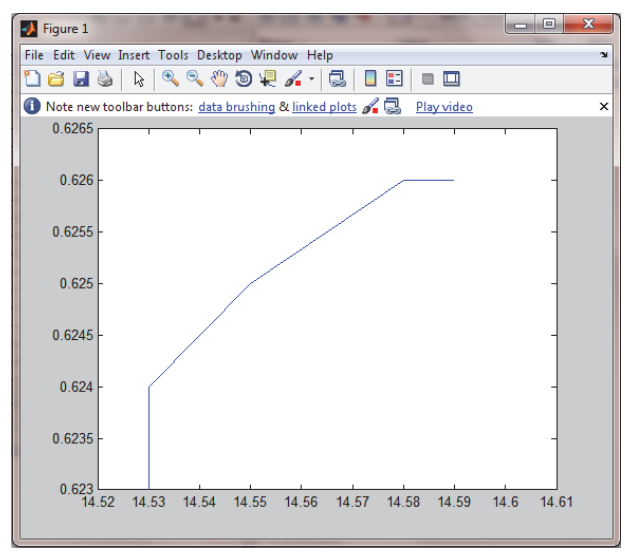

Figure 12. Power consumed versus time before the optimization

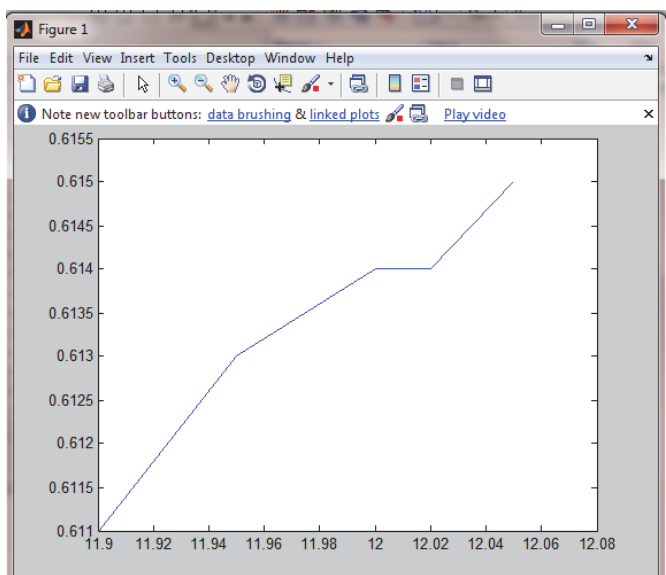

Figure 13. Power consumed versus time after the optimization 


\section{Conclusion}

As a conclusion based on the experiment, it shows that the less joint movement of arm robot manipulator consumed less energy. The arm robot has ability to do the pick and place task handling in order to achieve the target, the robot manipulator needs to use small joint movement to optimum utilization of energy consumption. Therefore, the minimum motor movement can produced less time taken to complete the pick and place task. Directly, it results on less energy will be use and will increase the robot arm performance.

\section{Acknowledgments}

The authors also would like to thank Ministry of Education Malaysia (MOE) and Center for Robotics and Industrial Automation, Faculty of Electrical Engineering, Universiti Teknikal Malaysia Melaka (UTeM) through grant PJP/2017/FKE/H18/S01524 for the financial assistance.

\section{References}

Bowling, A., \& Khatib, O. (1997). Design of Macro/ Mini Manipulators for Optimal Dynamic Performance. Proceedings of the IEEE International Conference on Robotics and Automation.

Clothier, Kurt. E., \& Shang, Y. (2010). A Geometric Approach for Robotic Arm Kinematics with Hardware Design, Electrical Design, and Implementation. Journal of Robotics, 1-10.

Hernandez, C., \& Poot, R. (2010). Design and Implementation of a System for Wireless Control of a Robot. IJCSI International Journal of Computer Science, 7(5), 191-197.

HHM Shah, Z., Kamis, M. F., Abdollah, CCK You, \& ZI Rizman. (2018b). Develop and implementation of voice recognition robotic car. International Journal of Engineering and Technology (UAE), 7(3.14 Special Issue 14), 242-249.

HNM Shah, M. Z. A., Rashid, M. F., Abdollah, Kamarudin, M. N., Lin, C. K., \& Kamis, Z. (2014). Biometric Voice Recognition in Security System. Indian Journal of Science and Technology, 7(2), 104-112.

HNM Shah, Z., Kamis, M. F., Abdollah, F., wasbari, N. M. Ali., \& Shah, A. A. M. (2018a). Develop and Implementation of Solar Ventilation System. Indonesian Journal of Electrical Engineering and Computer Science, 12(3), 1211-1221.

Kazim, M. N. F. M., Shah, H. N. M., \& Nasir. M. D. M. (2015). Theoretical Analysis on Energy Consumption for Industrial Robots. Applied Mechanics and Materials, 699, 846-852.

Lee, H. (2012). Optimization of Dual-arm Configurations for Multiple Object Handling. IEEE Journal of Pusan National University, 1291-1296.

Marizan, S., MIK Syaffiq, Azmi, S., Shah, H. N. M., \& Fakhzan, M. N. (2013). Simulation and Experimental Work of Kinematic Problems for Kuka Kr 5 Sixx R650 Articulated Robot. International Journal of Energy and Power Engineering Research, pp. 6-9.

Nakamura, Y., \& Hanafusa, H. (1987). Optimal redundancy control of robot manipulators. International Journal Robotics Res., 6(1), 32-42.

Oda, N., \& Murakami, T. (1995). A Robust Control Strategy of Redundant Manipulator by Workspace Observer. The Transaction of the Institute of Electrical Engineers of Japan. Vol.llS-D, 8, 991-996.

\section{Copyrights}

Copyright for this article is retained by the author(s), with first publication rights granted to the journal.

This is an open-access article distributed under the terms and conditions of the Creative Commons Attribution license (http://creativecommons.org/licenses/by/4.0/). 